were compared across four exclusive infection groups-HIV-seropositive-only, HCV-seropositive-only, HIV-HCV seropositive and HIV-HCV seronegative individuals.

Results Of 2969 IDU, 1.7\% were HIV-seropositive-only, 57.5\% were HCV-seropositive-only, $11.6 \%$ were HIV-HCV seropositive, and $29.2 \%$ were HIV-HCV seronegative. The proportion of IDU who were accurately aware of their negative or positive HIV infection status (based on concordance between self-report and laboratory result) was $85.7 \%$ among HIV-seropositive-only, $87.5 \%$ among HCV-seropositive-only, 78.7\% among HIV-HCV seropositives and $77.5 \%$ among HIV-HCV seronegatives. The highest proportions reporting needle borrowing (past 6 months 24.2\%) and high drug injecting frequency $(69.4 \%>$ once or twice per week) were in the HCV-seropositive-only group. The highest proportions reporting multiple sex partners (past 6 months $44.9 \%$ ) and no condom use at last sex (33.8\%) were among HIV-HCV seronegative IDU; this group was also least likely to have been tested for HIV or HCV (85.1\% and $80.6 \%$ respectively). Among those who were HIV-seropositive-only, $87.8 \%$ were under the recent care of a doctor and $74.2 \%$ were taking prescribed drugs for HIV. Among those HCVseropositive-only, $45.5 \%$ were under the recent care of a doctor and 13.1\% were taking prescribed drugs for HCV.

Conclusions Injecting and sexual risk behaviours were prevalent particularly among HCV-seropositive-only and seronegative IDU, respectively. Awareness of correct HIV infection status and frequency of HIV testing were lowest among seronegative IDU. These findings underscore the importance of routine and integrated HIV and HCV testing for at-risk IDU which may lead to higher levels of awareness for both HIV and HCV infections.

\section{P1-S2.25 HIV SEROSTATUS KNOWLEDGE, ABSENCE OF PREVIOUS TESTING AND SEXUAL BEHAVIOURS AMONG INJECTING DRUG USERS}

doi:10.1136/sextrans-2011-050108.82

\begin{abstract}
${ }^{1} \mathrm{~K}$ Blouin, ${ }^{1} \mathrm{R}$ Parent, ${ }^{2} \mathrm{P}$ Leclerc, ${ }^{3} \mathrm{C}$ Blanchette, ${ }^{1} \mathrm{M}$ Alary, ${ }^{2} \mathrm{C}$ Morissette, ${ }^{4} \mathrm{E}$ Roy, ${ }^{1} \mathrm{C}$ Claessens. Institut National de Santé Publique du Québec, Québec, Canada; ${ }^{2}$ Direction de Santé Publique de Montréal, Montréal, Canada; ${ }^{3}$ Centre de recherche du Centre hospitalier affilié universitaire de Québec, Québec, Canada; ${ }^{4}$ Université de Sherbrooke à Longueuil, Longueuil, Canada
\end{abstract}

Background Few studies have examined the association between HIV status knowledge and sexual behaviours among injection drug users (IDUs). We tested the hypothesis that IDUs who know their HIV positive status will have safer sexual practices than IDUs aware of their HIV negative status or never tested for HIV.

Methods IDUs who had injected in the past 6 months were recruited in harm reduction programs across the Province of Quebec and Ottawa, Canada. Participants completed a questionnaire including questions on sexual behaviours and provided saliva for HIV antibody testing. For IDUs with multiple participations, the last interview was selected. Data from 2003 to 2009 were analysed. Three groups were compared-IDUs aware of their positive HIV status $(n=510)$, IDUs aware of their HIV negative status $(n=2928)$ and IDUs never tested for HIV $(n=427)$. Proportions were compared using $\chi^{2}$ tests.

Results Male IDUs aware of their positive HIV status were less likely to have had sex in the last month (HIV positive-32.4\%, HIV negative $-47.2 \%$ and never tested $-55.0 \% ; \mathrm{p}<0.0001, \mathrm{n}=2741)$ and, among those sexually active, more likely to have used a condom at last sexual intercourse (HIV positive- $57.4 \%$, HIV negative- $-43.7 \%$ and never tested $-51.7 \% ; \mathrm{p}<0.005, \mathrm{n}=1249)$. This was not observed for women. In the last 6 months, the proportion of male IDUs who had always used condoms for vaginal or anal sex with their female sex partners was significantly higher in HIV positive than in HIV negative and in those never tested, for regular (54.3\%, 22.4\% and
$33.1 \%$, respectively, $\mathrm{p}<0.0001, \mathrm{n}=1131)$, casual $(77.4 \%, 54.4 \%$ and $51.2 \%$, respectively, $\mathrm{p}=0.0002, \mathrm{n}=933)$ and partners of whom they are a client $(86.7 \%, 69.7 \%$ and $42.1 \%$, respectively, $\mathrm{p}<0.02, \mathrm{n}=123)$. Women never tested for HIV were less likely than the other groups to use condoms with their regular partners (never tested-4.7\%, HIV positive-21.3\% and HIV negative $-20.2 \%$; $<<0.05, \mathrm{n}=550$ ) and their client sex partners (never tested-46.2\%, HIV positive-82.1\% and HIV negative-76.6\%; $\mathrm{p}<0.05, \mathrm{n}=259$ ). Women aware of their HIV positive status were more likely to report condom use with their casual sex partners, whereas those never tested were less likely (HIV positive-66.7\%, HIV negative-48.0\% and never tested-15.8\%; $\mathrm{p}<0.01, \mathrm{n}=250$ ).

Conclusions IDUs aware of their positive HIV serostatus reported more consistent condom use with their various types of sex partners than those aware of their HIV negative status or never tested.

\section{P1-S2.26 DRUG AND SEXUAL HIV RISK AMIONG INJECTION DRUG USERS - A LATENT CLASS ANALYSIS}

doi:10.1136/sextrans-2011-050108.83

S Noor. University of Texas School of Public Health, Houston, USA

Background Injection drug users (IDUs) are at increased risk of HIV infection because they are more likely to engage in high risk injection behaviours (eg, needle sharing) as well as in high risk sexual behaviours (eg, exchange sex). This analysis examines factors associated with HIV risk using a latent class approach.

Methods Our study includes 523 eligible injection drug users, recruited into the 2009 National HIV Behavioural Surveillance project. Using maximum likelihood we calculated the posterior probability of being in an HIV risk class from nine drug and sexual behaviours. We simultaneously fitted a multinomial regression model to identify socio-demographic factors associated with HIV risk class. Results We identified 3 HIV risk classes-high (42\%), moderate $(25 \%)$ and low risk (33\%). Compared to the high HIV risk class, homeless IDUs had lower odds to be in the moderate $(\mathrm{OR}=0.16$, $95 \%$ CI 0.04 to 0.70$)$ and in low risk HIV class (OR=0.28, 95\% CI 0.15 to 0.52$)$. Moreover, IDUs who were arrested in the past 12 month had also lower odds to be in low risk class $(\mathrm{OR}=0.52,95 \%$ CI 0.32 to 0.86 ) compared to high HIV risk class.

Conclusions Our results show that the majority of our IDUs were engaged in high HIV risk behaviours. Though temporality cannot be established due to the cross-sectional study design our findings indicate that homelessness and history of incarceration are associated with HIV risk. Interventions targeting system-level change may help to reduce the burden of HIV among the injection drug user population.

\section{Epidemiology poster session 2: Population: Vulnerable youth \\ P1-S2.27 RESPONSE OF TROUBLED YOUTH AND STIS}

doi:10.1136/sextrans-2011-050108.84

A lqbal Bhutta. Al-Murid Surgicaltian Hospital, Muzaffargarh, Pakistan

Description Pakistan, the second most populous Muslim nation in the world, has started to finally experience and confront the HIV/ AIDS epidemic. The country had been relatively safe from any indigenous HIV cases for around 2 decades, with most of the infections being attributable to deported HIV positive migrants from the Gulf States. However, the virus finally seems to have found a home-base, as evidenced by the recent HIV outbreaks among the injection drug user community. Extremely high-risk behaviour has 
also been documented among youth (school going and out of school). The weak government response coupled with the extremely distressing social demographics of this South-Asian republic also helps to compound the problem. The time is ripe now to prepare in advance, to take the appropriate measures to curtail further spread of the disease. If this opportunity is not utilised right now, little if at all could be done later. Islamic charities provide health, education and social services to millions of people in Pakistan. But in Pakistan still sexuality is a taboo topic. Strong hold of religious leaders on socio cultural pattern of community (attitude with extremism). Prevailing concepts to talk about sex considered as act of vulgarity and immoral activity. Word STIs and HIV/AIDS conceived as symbol of sexual delinquencies.

Method Through a Questionnaire data on knowledge, attitude, behaviour and practices related to STIs/HIV/AIDS was collected from 1200 male religious students and religious scholars from randomly selected Islamic religious centers. Baseline knowledge, attitude, acceptability of the concept were assessed.

Results According to KABP study $70 \%$ students have friends of opposite sex and due to strong religious values and restriction $30 \%$ have no friendship with opposite sex. Regarding nature of sex, $40 \%$ had kissing and only $18 \%$ had intercourse. During intercourse only $3 \%$ used condoms. $42 \%$ consider that condom is used only for family planning purpose. $56 \%$ answered that during intercourse use of condoms reduce sexual pleasure and enjoyment. 32\% youth use drugs and $38 \%$ did not know about STIs and HIV/AIDS. General discussions were also started with four Maderssas students and their teachers. These meetings addressed the sensitisation of religious scholars to the issue of HIV/AIDS and highlight the role of Maderssas in STIs and HIV prevention.

Conclusions Training of adolescent as peer educators is recommended. Ours being an Islamic society, such information should be given to youth in a way that does not challenge local norms and values. Problem-based learning and participatory education for improving knowledge and condom use and community-based interventions should be considered for STIs/HIV/AIDS prevention.

\section{P1-S2.28 SEXUALLY TRANSMITTED INFECTIONS IN SEXUALLY ABUSED CHILDREN AND ADOLESCENTS IN IBADAN, NIGERIA}

doi:10.1136/sextrans-2011-050108.85

${ }^{1} \mathrm{~S}$ A Fayemiwo, ${ }^{1} \mathrm{I}$ A Ayede, ${ }^{2} 00$ Olusanya, ${ }^{2} \mathrm{O}$ F Akinbami, ${ }^{1} \mathrm{R}$ A Bakare. ${ }^{1}$ University of Ibadan, Ibadan, Nigeria; ${ }^{2}$ University College Hospital, Ibadan, Nigeria

Background Sexual assault is a violent crime that affects men, women, and children of all ages. Sexually transmitted infections (STIs) may be transmitted during sexual assault. This study was aimed at finding the prevalence of sexually transmitted infections in potentially sexually abused children and adolescent in Ibadan.

Methods This is a descriptive cross-sectional survey of Children and adolescents referred for possible evaluation of sexual abuse at Special Treatment Clinic, University College Hospital, Ibadan between January 2006 and December 2008. Urethral, Endocervical and high vaginal swabs were collected to establish diagnosis after clinical examination and informed consent.

Results There were 18 children and adolescents with a mean age of 9.75 years ( $\mathrm{SD}=5.78$; range $2-18$ years). About $66.7 \%$ (12) had various STIs. The male to female ratio was $1: 8$. Five $(27.8 \%)$ had physical evidence of sexual assault at presentation, $4(22.2 \%)$ of which had hyperaemic labia and one had torn hymen. 12 (66.7\%) presented with vaginal discharge syndrome. The most common STI diagnosed was genital warts $(22.2 .0 \%)$. Other STIs diagnosed were vaginal candidiasis $(16.7 \%)$, bacterial vaginosis $(11.1 \%)$ and HIV (5.6\%). There was no statistical significance between HIV infection and other STIs ( $p>0.05)$.
Conclusion Our study revealed high prevalence of sexually transmitted infections among the sexually abused children and adolescents. Screening for infection should be mandatory in presumed sexually abused girls with vaginal discharge and ideally should be undertaken in all children presenting at STI clinics for evaluation of sexual abuse.

\section{P1-S2.29 RISKY SEXUAL PRACTICES AMONG YOUTH IN OUEBEC CARE CENTERS}

doi:10.1136/sextrans-2011-050108.86

${ }^{1}$ Gilles Lambert, ${ }^{2}$ Nancy Haley, ${ }^{3}$ Sandrine Jean, ${ }^{3}$ Claude Tremblay, ${ }^{2}$ JeanYves Frappier, ${ }^{4}$ Joanne Otis, ${ }^{5}$ Elise Roy. ${ }^{1}$ Institut national de santé publique du Québec, Montréal, Canada; ${ }^{2}$ Hospitalier Sainte-Justine, Université de Montréal, Canada, ${ }^{3}$ Direction de santé publique, agence de la santé et des services sociaux de Montréal, Canada; ${ }^{4}$ Université du Québec à Montréal, Canada; ${ }^{5}$ Université Sherbrooke, Canada

Background Adolescents in Youth Protection facilities are a vulnerable population, with difficult life trajectories; many of their behaviours are health compromising.

Method Youth aged 14-17, living in semi-urban and urban youth centers in Quebec were recruited on a volunteer basis to participate in the study. Socio-demographic, drug use, sexual behaviours and health service utilisation data were obtained using a structured, faceto-face interview. A urine sample was collected to test for chlamydia and gonorrhoea.

Results Between July 2008 and May 2009, 578 youth were interviewed-( $0-58 \%)$; median age- $0-16$; +15 . The majority of youth were sexually active (89\%); two thirds experienced voluntary coitarche before 14 years of age. Median number of lifetime partners was 6 ( $0-8,9-5)$. Over a third (41\%) reported group sexual activities. A large proportion of youth experienced $50 \%$ or more of their sexual activities under the influence of alcohol-18\%, cannabis-37\%, other drugs-18\%. Lifetime history of "never or rarely" using condoms was $24.7 \%$ for vaginal relations and $42.1 \%$ for anal relations ( $₫-33 \%$, $+-55 \%$ ). Protection used during last vaginal activity was-double protection (condom and another contraceptive method) $-25 \%$; condom only-32\%; contraceptive method without condom-20\%; no protection-24\%. A quarter of girls (28\%) and boys (27\%) reported an unplanned pregnancy (lifetime). Prevalence of chlamydia was-girls $9 \%$, boys $1.9 \%$. No cases of gonorrhoea were documented.

Conclusions Youth in Quebec care centers report many risky sexual behaviours, often associated with drug and alcohol use. Only a quarter of youth used protection to prevention both STIs and pregnancy during their last sexual activity. Their sejour in residential care is an opportune moment to screen these youth for risk behaviours that may compromise their future health and to provide them with personalised prevention education and health services adapted to their reality.

\section{P1-S2.30 STI AMONG VULNERABLES YOUTH ATTENDING FREE TARGETED HIV COUNSELLING AND TESTING SERVICES INCLUDING AND STI DIAGNOSIS AND MANAGEMENT IN BENIN, WEST AFRICA}

doi:10.1136/sextrans-2011-050108.87

B N Marguerite, B A Amour. Population Service International, Benin, Cotonou, Benin

Background In collaboration with two health facilities and a mobile clinic, Counselling and Testing (CT) services was implemented in two departments of Benin (Atacora and Donga) trough a project funded by the Kreditanstalt für Wiederaufbau (KfW) Germany. These interventions targeted vulnerable youth (15-24) and included 